\title{
SUV39H1-DNMT3A-mediated epigenetic regulation of Tim-3 and galectin-9 in the cervical cancer
}

\author{
Li Zhang' ', Sijuan Tian', Minyi Zhao', Ting Yang' ', Shimin Quan' ', Qing Yang ${ }^{1}$, Lihua Song ${ }^{2 *}$ \\ and Xiaofeng Yang ${ }^{1 *}$ (D)
}

\begin{abstract}
Background: Methylation of histone 3 at lysine 9 (H3K9) and DNA methylation are epigenetic marks correlated with genes silencing. The tumor microenvironment significantly influences therapeutic responses and clinical outcomes. The epigenetic-regulation mechanism of the costimulatory factors Tim-3 and galectin-9 in cervical cancer remains unknown.

Methods: The methylation status of HAVCR2 and LGALS9 were detected by MS-PCR in cervical cancer tissues and cell lines. The underlying molecular mechanism of SUV39H1-DNMT3A-Tim-3/galectin-9 regulation was elucidated using cervical cancer cell lines containing siRNA or/and over-expression system. Confirmation of the regulation of DNMT3A by SUV39H1 used ChIP-qPCR.

Results: SUV39H1 up-regulates H3K9me3 expression at the DNMT3A promoter region, which in turn induced expression of DNMT3A in cervical cancer. In addition, the mechanistic studies indicate that DNMT3A mediates the epigenetic modulation of the HAVCR2 and LGALS9 genes by directly binding to their promoter regions in vitro. Moreover, in an in vivo assay, the expression profile of SUV39H1 up-regulates the level of H3K9me3 at the DNMT3A promoter region was found to correlate with Tim-3 and galectin-9 cellular expression level.
\end{abstract}

Conclusion: These results indicate that SUV39H1-DNMT3A is a crucial Tim-3 and galectin-9 regulatory axis in cervical cancer.

Keywords: Cervical cancer, SUV39H1, H3K9me3, DNMT3A, Tim-3, Galectin-9

\section{Background}

Cervical cancer is the fourth common female malignancy worldwide [1]. In 2018, there was an estimated 569,847 new cases of cervical cancer and 311,365 deaths occurred worldwide [2]. High-risk human papillomavirus (HRHPV) caused almost all cervical cancer [3]. Persistent HR-HPV infection caused chronic microenvironment

\footnotetext{
*Correspondence: lihuas@sjtu.edu.cn; yxf73@163.com

1 Department of Gynecology and Obstetrics, The First Affiliated Hospital of Xi'an Jiaotong University, No.277 West Yanta Road, Xi'an 710061, China ${ }^{2}$ School of Agriculture and Biology, Shanghai Jiao Tong University, Shanghai 200240, China
}

changes of cervix. During carcinogenesis, over-adapted cancer cells eluded cytotoxic tumor infiltrating lymphocytes in a scenario of immune-tolerance driven by T-regulatory cells so that immune response is blocked [4]. T-cell immunoglobulin and mucin-domain containing-3 (Tim-3) negatively regulates Th1 immunity, once Tim-3 binds to its ligand galectin-9 could inhibit Th1 and Th17 responses by hampering their expansion, its mediating immune exhaustion in tumor microenvironment [5-7]. Tim $-3^{+} \mathrm{CD} 4^{+} \mathrm{T}$ cells represent the functional regulatory T cells which contribute to the formation of the immunesuppressive in human cervical cancer [8]. 
The epigenetic regulation of genes is critical for gene's transcription [9]. DNA methylation is participated in gene expression changes that occur in cervical cancer [10]. Our previous study revealed that EZH2H3K27me3-DNMT3A mediates the epigenetic regulation of the negative stimulatory molecules, Tim-3 and galectin-9 in cervical cancer which is associated with HPV18 infection [11]. Trimethylation of histone 3 lysine 9 (H3K9me3) at gene promoter regions is an important epigenetic mechanism that silences genes expression [12, 13] and SUV39H1 is H3K9me3-specific histone methyltransferase [14].

In present study, we identified an important role of histone and DNA methylation marks in regulating costimulatory factors Tim- 3 and galectin- 9 expression in cervical cancer. The relevant mechanism is mediated by the inhibition of Tim-3 and galectin-9 through recruiting DNMT3A to their promoter regions. SUV39H1 targeted DNMT3A by increasing the level of H3K9me3 at the DNMT3A promoter region so that repressed Tim-3 and galectin- 9 expression by DNA methylation in cervical cancer. These results represent a significant step forward in understanding the contribution of SUV39H1 and DNMT3A to cervical cancer progression and providing a potential target for epigenetic-based cervical cancer therapy.

\section{Materials and methods}

Patients and samples

24 cervical cancer tissues, accordingly matched peri-carcinomatous tissues and 16 normal cervical tissues were obtained from the First Affiliated Hospital of Xi'an Jiaotong University between January 2014 and December 2017. All patients were diagnosed by two senior pathologists and none had received chemotherapy or radiotherapy prior to surgery. The cervical cancer samples were collected as previous described [15]. After the tissues were dissected, each sample was washed with sterilized PBS thrice and stored at $-80{ }^{\circ} \mathrm{C}$. All procedures were performed on ice.

\section{Data mining}

Oncomine database (www.oncomine.org) was used to detect the HAVCR2 and LGALS9 mRNA expression levels in cervical cancer and normal cervix tissues. The correlation between HAVCR2 and LGALS9 expression was studied by the data obtained from the GEPIA database (http://gepia.cancer-pku.cn/).

\section{Cell lines and culture conditions}

The cervical cancer cell lines SiHa, HeLa and C33A were obtained from Cell Bank, Shanghai Institutes for Biological Sciences, Chinese Academy of Sciences, Shanghai.
All cell lines were cultured in high glucose Dulbecco's Modified Eagle's Medium (DMEM) (HyClone, USA) supplemented with $10 \%$ fetal bovine serum (FBS) (Biological Industries, Israel) at $37^{\circ} \mathrm{C}$ in an atmosphere of $5 \% \mathrm{CO}_{2}$.

\section{Lentivirus vectors and stable expression cell lines construction}

Lentiviral vector preparation of Plenti-CMV-puro-Dest vector containing SUV39H1 fragment. The SUV39H1 fragment was cloned from the genomic DNA of SiHa. DNA fragment treated with Kpn1 (TaKaRa, China) and Xho1 (TaKaRa, China) and then the target gene was linked to entry vector pENTR-MCS. Two-plasmid of Plenti-CMV-puro-Dest and pENTR-MCS recombination reactions were performed using LR Clonase II (Invitrogen, USA). Using Lip2000 (Invitrogen, USA) to transfect plasmid into $\mathrm{SiHa}$ and HeLa cell lines. The transduced cells were then selected by puromycin. Stably transduced cells were maintained in culture in the presence of puromycin. The cell lines were named SiHa-SUV39H1, HeLaSUV39H1, successively. The expression level of SUV39H1 was determined by western blotting.

\section{RNA interference}

$\mathrm{SiHa}$ and HeLa cell lines were transfected with scramble, SUV39H1 and DNMT3A specific siRNA (GenePharma, China), the following siRNA oligos for SUV39H1 and DNMT3A are listed in Table 1. The siRNAs respectively using X-tremeGENE siRNA Transfection Reagent (4476115001, Roche, Germany) and analyzed for SUV39H1 and DNMT3A expression levels by western blotting. All cell lines were named SUV39H1-siRNA and DNMT3A-siRNA, successively.

\section{5-Aza-2'-deoxycytidine treatment}

$1.0 \times 10^{5} /$ well $\mathrm{SiHa}$, HeLa and C33A cells were cultured in 6-well plates in DMEM with $10 \% \mathrm{FBS}$, after $24 \mathrm{~h}$, the medium was replaced with fresh medium containing $0 \mu \mathrm{M}, 2.5 \mu \mathrm{M}$ or $5 \mu \mathrm{M}$ 5-Aza-2'-deoxycytidine (5-AzaCdR) (Sigma, USA). The medium containing 5-Aza-CdR was replaced every $24 \mathrm{~h}$ during a 72 -h period [15].

\section{DNA extraction, bisulfite modification \\ and methylation-specific PCR (MS-PCR)}

Genomic DNA was isolated from cells and tissues using TaKaRa Mini BEST Universal Genomic DNA Extraction Kit (TaKaRa, China) according to the manufacturer's instruction. DNA modification was done as previous described [15], in briefly, $500 \mathrm{ng}$ genomic DNA was bisulfite-modified by EZ DNA Methylation-Gold ${ }^{\mathrm{TM}}$ Kit (Zymo Research, USA). Modified DNA templates were used for MS-PCR with Zymo TaqTM PreMix (E2003, Zymo Research, USA) following the instructions of the 
Table 1 Primer sequences

\begin{tabular}{|c|c|c|}
\hline Name & Application & Sequence \\
\hline DNMT3A-ChIP-F1 & ChIP-qPCR & $\begin{array}{l}\text { ATCATCAGTAGGGCGGGGTGG } \\
\text { CCAC }\end{array}$ \\
\hline DNMT3A-ChIP-R1 & ChIP-qPCR & $\begin{array}{l}\text { CTCCAATGCTTCCAGGTCCCT } \\
\text { CCGT }\end{array}$ \\
\hline DNMT3A-ChIP-F2 & ChIP-qPCR & $\begin{array}{l}\text { TTGGAGAACCTCCCGAAGGAA } \\
\text { AACC }\end{array}$ \\
\hline DNMT3A-ChIP-R2 & ChIP-qPCR & $\begin{array}{l}\text { GCCACCCTTTTAGCGTCACAG } \\
\text { AACC }\end{array}$ \\
\hline DNMT3A-ChIP-F3 & ChIP-qPCR & $\begin{array}{l}\text { CGTTGGGGGGGCGGGTGCTGG } \\
\text { GCTG }\end{array}$ \\
\hline DNMT3A-ChIP-R3 & ChIP-qPCR & $\begin{array}{l}\text { TGACTGGCACAGGACATGGCG } \\
\text { TGCT }\end{array}$ \\
\hline DNMT3A-ChIP-F4 & ChIP-qPCR & $\begin{array}{l}\text { CATGGGGAAGGAGAACAGCCC } \\
\text { CCAC }\end{array}$ \\
\hline DNMT3A-ChIP-R4 & ChIP-qPCR & $\begin{array}{l}\text { GCACTGGAAGACTGAAAGATT } \\
\text { TCAT }\end{array}$ \\
\hline HAVCR2-ChIP-F1 & ChIP-qPCR & $\begin{array}{l}\text { GTGGAAAAAATCTGTCACTTA } \\
\text { GGGG }\end{array}$ \\
\hline HAVCR2-ChIP-R1 & ChIP-qPCR & $\begin{array}{l}\text { ATTTTTAGTAGAGACGGGGTT } \\
\text { TCTC }\end{array}$ \\
\hline HAVCR2-ChIP-F2 & ChIP-qPCR & $\begin{array}{l}\text { CCTGTAATCCCAGCTACTCAG } \\
\text { GAGG }\end{array}$ \\
\hline HAVCR2-ChIP-R2 & ChIP-qPCR & $\begin{array}{l}\text { CTTGTTCAATGTGTGTACTTC } \\
\text { CCAT }\end{array}$ \\
\hline HAVCR2-ChIP-F3 & ChIP-qPCR & $\begin{array}{l}\text { CCCAATGCATTTAATGGCATA } \\
\text { AATG }\end{array}$ \\
\hline HAVCR2-ChIP-R3 & ChIP-qPCR & $\begin{array}{l}\text { CAGCCACACTCCCATAACTGA } \\
\text { GGTA }\end{array}$ \\
\hline HAVCR2-ChIP-F4 & ChIP-qPCR & $\begin{array}{l}\text { GGAACTCAACACTTTCTGATC } \\
\text { ATTC }\end{array}$ \\
\hline HAVCR2-ChIP-R4 & ChIP-qPCR & $\begin{array}{l}\text { GACTTTGACCTTCAAACTTCC } \\
\text { AACT }\end{array}$ \\
\hline LGALS9-ChIP-F1 & ChIP-qPCR & $\begin{array}{l}\text { GGTAGAGTAAAATGTACAGAT } \\
\text { CCTG }\end{array}$ \\
\hline LGALS9-ChIP-R1 & ChIP-qPCR & $\begin{array}{l}\text { GCGAGACCTTGTCTCTACTAA } \\
\text { AAAT }\end{array}$ \\
\hline LGALS9-ChIP-F2 & ChIP-qPCR & $\begin{array}{l}\text { TCAGCCTCCCAATGTGCTGAA } \\
\text { TTAC }\end{array}$ \\
\hline LGALS9-ChIP-R2 & ChIP-qPCR & $\begin{array}{l}\text { CCAGATCCAAACTTGACTTGA } \\
\text { AGTG }\end{array}$ \\
\hline LGALS9-ChIP-F3 & ChIP-qPCR & $\begin{array}{l}\text { TCCTGTGGCCTAGCTCCTTTT } \\
\text { TATT }\end{array}$ \\
\hline LGALS9-ChIP-R3 & ChIP-qPCR & $\begin{array}{l}\text { AGAAAAACTGCTTGGTGAGTT } \\
\text { GTAA }\end{array}$ \\
\hline LGALS9-ChIP-F4 & ChIP-qPCR & $\begin{array}{l}\text { CACATATGTTTTCCTTTCTCT } \\
\text { TGGG }\end{array}$ \\
\hline LGALS9-ChIP-R4 & ChIP-qPCR & $\begin{array}{l}\text { ACACCTGTGGTCTCAGCTACA } \\
\text { TGGG }\end{array}$ \\
\hline HAVCR2-ML & MS-PCR & $\begin{array}{l}\text { TATAAAATGAGAAATTGGTCG } \\
\text { GGCG }\end{array}$ \\
\hline HAVCR2-MR & MS-PCR & $\begin{array}{l}\text { TTACAAACATATACCACCACC } \\
\text { CCGA }\end{array}$ \\
\hline HAVCR2-UL & MS-PCR & $\begin{array}{l}\text { GAAATTGGTTGGGTGTGGTGG } \\
\text { TTAT }\end{array}$ \\
\hline HAVCR2-UR & MS-PCR & $\begin{array}{l}\text { TATACCACCACCCCAAATAAT } \\
\text { TTTA }\end{array}$ \\
\hline
\end{tabular}

Table 1 (continued)

\begin{tabular}{|c|c|c|}
\hline Name & Application & Sequence \\
\hline LGALS9-9-ML & MS-PCR & $\begin{array}{l}\text { TTTTCGAGATAGGTTTGCGAT } \\
\text { TTTG }\end{array}$ \\
\hline LGALS9-9-MR & MS-PCR & $\begin{array}{l}\text { AATACCGACACCCTTCAATCA } \\
\text { CCAC }\end{array}$ \\
\hline LGALS9-9-UL & MS-PCR & $\begin{array}{l}\text { GAGTTTTTGAGATAGGTTTGT } \\
\text { GATT }\end{array}$ \\
\hline LGALS9-9-UR & MS-PCR & $\begin{array}{l}\text { ATACCAACACCCTTCAATCAC } \\
\text { CACA }\end{array}$ \\
\hline SUV39H1-sense & Gene silencing & CCUUCGUGUACAUCAAUGATT \\
\hline SUV39H1-anti-sense & Gene silencing & UCAUUGAUGUACACGAAGGTT \\
\hline DNMT3A-sense & Gene silencing & GCCAAGGUCAUUGCAGGAATT \\
\hline DNMT3A-anti-sense & Gene silencing & UUCCUGCAAUGACCUUGGCTT \\
\hline Negative control-sense & Gene silencing & UUCUCCGAACGUGUCACGUTT \\
\hline Negative control-sense & Gene silencing & ACGUGACACGUUCGGAGAATT \\
\hline
\end{tabular}

ChIP chromatin immunoprecipitation, $R T-P C R$ reverse transcription-polymerase chain reaction, $F$ forward primer, $R$ backward primer, $M S-P C R$ methylationspecific-polymerase chain reaction, $M L / U L$ methylation/unmethylation forward primer, MR/UR methylation/unmethylation backward primer

manufacturer. The primers used in MS-PCR are listed in Table 1. The annealing temperature for the methylated primers of $H A V C R 2$ and LGALS9 were $60^{\circ} \mathrm{C}$ and $60{ }^{\circ} \mathrm{C}$ while that for the unmethylated primers were $55{ }^{\circ} \mathrm{C}$ and $56.3{ }^{\circ} \mathrm{C}$. The MS-PCR products were separated on a $2 \%$ agarose gel, stained with Gelview and visualized under ultraviolet illumination (Bio-Rad, USA). Methylation level was calculated by the ratio of methylated and unmethylated levels. Grey value of each band represented its relative expression and was measured by Image J Software. Each reaction was performed in triplicate.

\section{Western blotting analysis}

Cells were treated with RIPA Lysis Buffer which contained $1 \mathrm{mM}$ PIC and $1 \mathrm{mM}$ PMSF. Proteins were separated by SDS-PAGE and electroblotted onto PVDF membrane (Millipore, USA), then blocked $1 \mathrm{~h}$ at room temperature in $5 \%$ skim milk and incubated with primary antibodies for overnight at $4{ }^{\circ} \mathrm{C}$ followed by HRP conjugated secondary antibodies for $1 \mathrm{~h}$ at room temperature. The secondary antibodies are as follows: HRP-conjugated rabbit anti-mouse IgG (1:5000 dilution, D110273-0100, BBI Life Sciences, China), HRPconjugated goat anti-rabbit IgG (1:5000 dilution, 31460, PIONEER, China). Chemiluminescence signal was detected following incubation with enhanced chemiluminescence reagent (Millipore, USA). Grey value of each band was measured with Image J Software. The primary antibodies are listed in Table 2. 
Table 2 Primary antibodies

\begin{tabular}{lllll}
\hline Antibody & Source & Dilution & Cat number & Application \\
\hline H3K9me3 & Cell Signaling Technology & $1: 50 / 1: 1000$ & 13969 & ChIP, WB \\
SUV39H1 & Cell Signaling Technology & $1: 1000$ & 8729 & WB \\
Tim-3 & Abcam & $1: 50$ & ab47997 & IF \\
Tim-3 & Abcam & $1: 250 / 1: 250$ & ab185703 & WB, IHC \\
Galectin-9 & Abcam & $1: 200$ & ab123712 & WB \\
Galectin-9 & Abcam & $1: 250 / 1: 200$ & ab69630 & IF, IHC \\
DNMT3A & Abcam & $1: 50 / 1: 250$ & ab13537 & ChIP,WB \\
IgG & Cell Signaling Technology & $1: 500$ & 2729 & ChIP \\
Histone H3 & Cell Signaling Technology & $1: 50$ & 4620 & ChIP \\
B-actin & TransGen Biotech & $1: 500$ & HC201-01 & WB \\
\hline
\end{tabular}

ChIP chromatin immunoprecipitation, WB western blotting, IF immunofluorescence, IHC immunohistochemical

\section{Chromatin immunoprecipitation (ChIP) assay and ChIP-qPCR}

ChIP assays were carried out using the Simple ChIP Enzymatic Chromatin IP Kit (Cell Signaling Technology, USA) according to the manufacturer's instructions. The DNMT3A, HAVCR2 and LGALS9 promoter regions were detected by qPCR using promoter DNA-specific primers. The primers are listed in Table 1 . We used the cycle threshold (CT) as the representative point. The relative expression of genes in each group (fold-change compared with control) was calculated using the formula: $R Q=2^{-\Delta \Delta C t}$. Each reaction was performed in triplicate. The antibodies are listed in Table 2.

\section{Immunofluorescence staining}

$\mathrm{SiHa}$ and HeLa cells were incubated with primary antibodies overnight at $4{ }^{\circ} \mathrm{C}$. After washing three times, the cells were incubated with R-conjugated Donkey antirabbit IgG (1:200 dilution, sc-2095, Santa Cruz Biotechnology, USA) and FITC-conjugated Donkey anti-goat IgG (1:200 dilution, EK033, Zhuangzhibio, China) for $1 \mathrm{~h}$ at room temperature. Finally, DAPI Fluoromount-G (SouthernBiotech, USA) was used to counterstain the cell nuclei. The fluorescent was detected, and images were taken by Leica inverted fluorescence microscope. The primary antibodies are listed in Table 2.

\section{Immunohistochemical staining}

Human cervical cancer specimens were fixed with neutral formalin, embedded in paraffin, and sectioned at a thickness of $4 \mu \mathrm{m}$. Sections were deparaffinized in xylene and rehydrated in a graded alcohol series. Antigen retrieval was performed using $0.01-\mathrm{M}$ citrate buffer and 2 min of boiling. Hydrogen peroxide was applied to block endogenous peroxidase activity, and then sections were incubated with normal goat serum (SP-9001,
Zsbio, China) to block nonspecific protein binding. Sections stained with primary antibody for Tim-3 and galectin-9 were incubated overnight at $4{ }^{\circ} \mathrm{C}$. Sections were stained in parallel with PBS as a negative control. Tim-3 and galectin-9 expression were then detected using $\mathrm{DAB}$, and slides were counterstained with hematoxylin. Slides were view at $400 \times$ magnification. The primary antibodies are listed in Table 2.

\section{Xenograft mouse model}

Female BALB/c nude mice (4-week-old) used in this study and were maintained in a specific-pathogen-free (SPF) condition facility. Mouse injected subcutaneously with $1 \times 10^{7} \mathrm{SiHa}-\mathrm{SUV} 39 \mathrm{H} 1 / \mathrm{HeLa}-\mathrm{SUV} 39 \mathrm{H} 1$ cells were randomly divided into four groups when tumor volumes were around $100 \mathrm{~mm}^{3}$ : (1/2) SiHa-mock/HeLa-mock control groups; (3/4) SiHa-SUV39H1/HeLa-SUV39H1 groups. Two diameters of the individual tumor were measured by electronic slide caliper every 2 days. Tumor volume was calculated using the following formula: tumor volume $\left(\mathrm{mm}^{3}\right)=0.5 \times$ length $\times$ width $^{2}$. Mice were monitored for 21 days, at which time mice were euthanized and tumors and organs were extracted.

\section{Statistical analysis}

Statistical analyses were performed using GraphPad Prism 7 software (GraphPad Software, USA). Paired t test and one-way ANOVA analysis were carried out on samples within groups. The $P$ value of $<0.05$ was considered statistically significant. The $P$ values are represented as ${ }^{* *} P<0.01,{ }^{*} P<0.05$. The data are presented as mean \pm standard error of the mean (SEM). All experiments were independently repeated at least thrice, with consistent results. 


\section{Results}

Tim- $\mathbf{3}$ and galectin- 9 expression were increased due to genes methylation level decreased in cervical cancer Using the Oncomine databases (https://www.oncom ine.org/), the mRNA expression levels of HAVCR2 and LGALS9 were compared between cervical cancer and normal cervical samples. The results indicated that the expression levels of HAVCR2 and LGALS9 were all higher in cervical cancer than in normal cervical samples (Fig. 1a, b). Furthermore, HAVCR2 was positively corrected with LGALS9 $(\mathrm{R}=0.26, P<0.05)$ based on Gene Expression Profiling Interactive Analysis (GEPIA) dataset (http://gepia.cancer-pku.cn/) (Fig. 1c). Hence HAVCR2 has a positive correlation with $L G A L S 9$ in cervical cancer. The expression of Tim- 3 and galectin- 9 protein in cancer tissues were higher than in normal cervix tissues (Fig. 1d, e). The detail data of patients' clinicopathological is shown in Table 3.

The online software "MethPrimer" (http://www.uroge ne.org/methprimer/) profiled CpG island in the region that was located from -2000 to -200 bp upstream from ATG, the transcription starts site (TSS) in the HAVCR2 and LGALS9 promoter regions respectively (Fig. 1f). One pair of primer was designed to amplify the genes promoter regions respectively. HAVCR2 and LGALS9 promoter regions in cervical cancer tissues displayed hypermethylation status in normal cervical tissues (Fig. 1g, h), possibly leading to the inhibition of transcriptional activity of genes in normal cervical tissues. Immunohistochemistry results revealed that both Tim-3 and galectin-9 expressed in tumor cells of cervical cancer tissues, and galectin-9 also showed evident staining in peritumoral inflammatory infiltrate of cervical cancer tissues (Fig. 1i).

Tim-3 and galectin- 9 expression were reversed by alter the methylation status in the promoter regions of HAVCR2 and LGALS9 in cervical cancer cells

HAVCR2 and LGALS9 promoter regions in SiHa, HeLa and C33A cells were all partially methylated (Fig. 2a). The Tim-3 and galectin-9 were both expressed in SiHa, HeLa and C33A cells (Fig. 2b). To identify whether the methylation status in the promoter regions regulate the expression of these genes at the transcription level, the mRNA expression levels of HAVCR2 and LGALS9 in SiHa, HeLa and C33A cell lines after treatment with DNA demethylation reagent 5 -Aza-CdR were detected. The results suggested that the expression levels of $H A V C R 2$ and LGALS9 mRNA in SiHa, HeLa and C33A cells were increased in dose-dependent manner after cellular DNA demethylation (Fig. 2c, d). It illustrated the Tim-3 and galectin- 9 expression were reversed by 5 -Aza-CdR, which promoted the expression of these genes at the transcriptional level. Immunofluorescence assay showed that the $\mathrm{SiHa}$ and HeLa cells both staining cytoplasm and nuclear Tim-3 and galectin-9 (Fig. 2e).

\section{Tim-3 and galectin-9 expression were repressed by DNMT3A through mediated DNA methylation}

The study found that knocking-down DNMT3A activated Tim-3 and galectin-9 expression (Fig. 3a, b), accompanied by decreased DNA methylation level of the genes' promoter regions in $\mathrm{SiHa}$ and HeLa cells (Fig. 3c, d), suggesting that DNMT3A play a critical role in Tim-3 and galectin-9 expression regulation. The ChIP analysis revealed enhanced binding of DNMT3A (Fig. 3f, h) to the HAVCR2 and LGALS9 promoter regions (Fig. 3e, g) in $\mathrm{SiHa}$ and HeLa cells. Altogether, these results suggested that DNMT3A-mediated DNA methylation contributes to the transcriptional silencing of HAVCR2 and LGALS9.

\section{SUV39H1 mediated DNMT3A expression}

through up-regulating $\mathrm{H} 3 \mathrm{~K} 9 \mathrm{me} 3$ in cervical cancer cells

SUV39H1 is the histone methyltransferase (HMTase) of histone $\mathrm{H} 3$ lysine 9 trimethylation (H3K9me3) [16]. SUV39H1 recognizes trimethylated H3K9 (H3K9me3) via its chromodomain (CD), and enriched H3K9me3 afterwards [17]. The H3K9me3 and DNMT3A both expressed in SiHa, HeLa and C33A cells (Fig. 4e).

As shown in Fig. 4b, overexpressed SUV39H1 in SiHa and HeLa cells (Fig. 4a) significantly increased H3K9me3 and DNMT3A expression levels. Knocking-down SUV39H1 expression in $\mathrm{SiHa}$ and HeLa cells displayed dramatically down-regulation expression of $\mathrm{H} 3 \mathrm{~K} 9 \mathrm{me} 3$ and DNMT3A (Fig. 4c, d). Collectively, these results indicated that SUV39H1 participate in the regulation of DNMT3A through changing H3K9me3 expression level in cervical cancer cells.

In a screening for epigenetic mechanism that regulating DNMT3A expression, ChIP analysis revealed that the $\mathrm{SiHa}$ and HeLa cells exhibit the highest H3K9me3 level in DNMT3A promoter region which upstream of the transcription initiation region (Fig. 4f). H3K9me3 expression level up-regulated on the -1000 to +1 region of the promoter region of DNMT3A (Fig. $4 \mathrm{~g}, \mathrm{~h}$ ). Taken together, above results revealed that $\mathrm{SUV} 39 \mathrm{H} 1$ regulated the expression of DNMT3A through elevating H3K9me3 level at the DNMT3A promoter in cervical cancer cells.

\section{The methylation status of HAVCR2 and LGALS9 affected by SUV39H 1 in cervical cancer cells}

After have been determining the baseline levels of DNA methylation on HAVCR2 and LGALS9 promoter regions among cervical cancer cell line, evaluation whether SUV39H1 mediated DNA methylation 
a

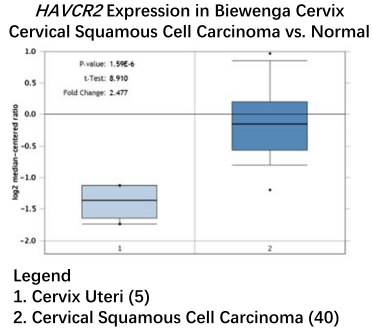

b

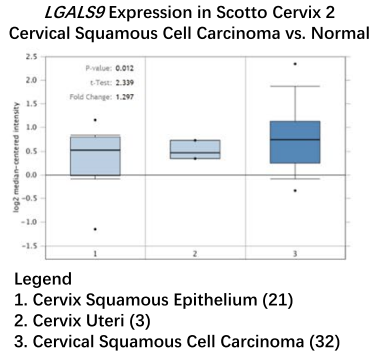

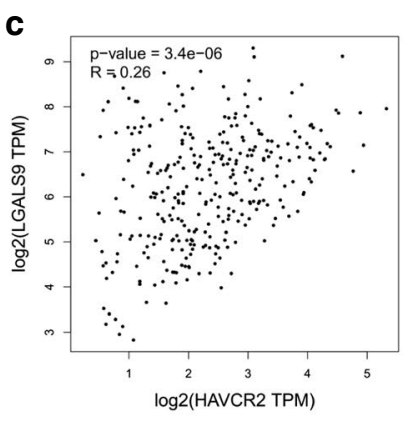

e

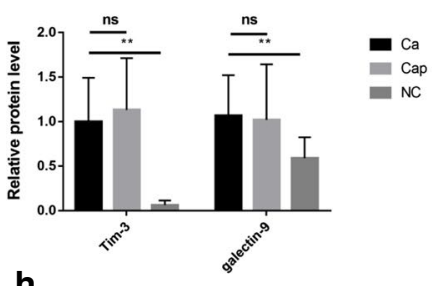

h

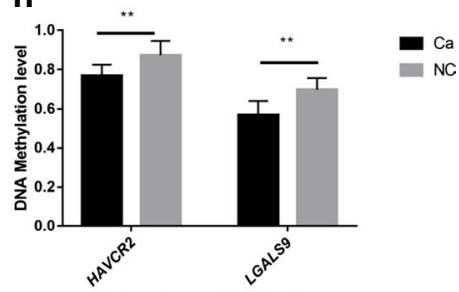

NC
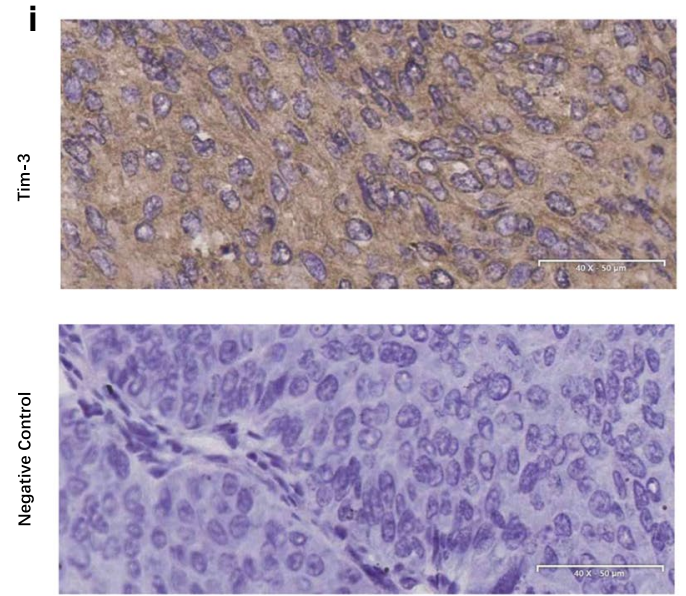

g

HAVCR2

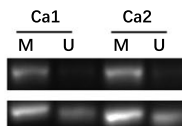

LGALS9
LGALS9
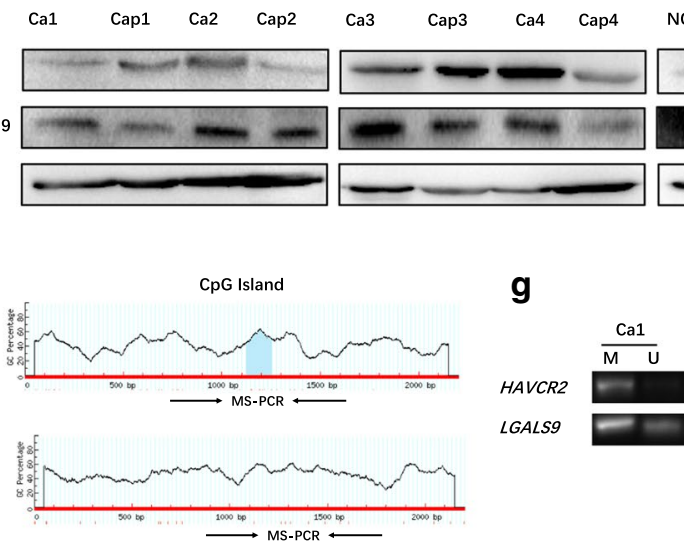

NC3

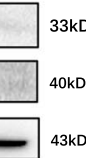

Fig. 1 The expression of Tim-3 and galectin-9 in cervical cancer tissues and the genes methylation level. $\mathbf{a}$, $\mathbf{b}$ An overview of mRNA levels of HAVCR2 and LGALS9 in cervical cancer based on Oncomine database. c The correction between HAVCR2 and LGALS9 in cervical cancer, analyzed by GEPIA database. $\mathbf{d}$, e The protein levels of Tim-3 and galectin-9 in cervical cancer (Ca) $(n=24)$, para-carcinoma (Cap) $(n=24)$ and normal cervical tissues (NC) $(n=16)$ detected by western blotting. Blot images of four representative samples are shown from each group. $\mathbf{f}$ Predicted $\mathrm{CpG}$ islands in the promoter regions of HAVCR2 and LGALS9. Numbers indicate the positions in bp relative to the transcription start site. The blue region represents the $\mathrm{CpG}$ islands and the red vertical bars are the $\mathrm{CpG}$ loci in these input sequences. $\mathbf{g}$, $\mathbf{h}$ Methylation level of HAVCR2 and LGALS9 promoter regions in cervical cancer $(C a)(n=9)$ and NC $(n=9)$ detected by MS-PCR. (M methylated, $U$ unmethylated); methylated and unmethylated levels of genes were quantified as $M / M+U \%$ and $U / M+U \%$, respectively. i Positive immunohistochemistry staining of Tim-3 and galectin-9 and negative control in representative cervical cancer samples. Magnification, $\times 400 .{ }^{* *} P<0.01$, ns not significant 
Table 3 Patients' clinicopathological details $(\mathbf{n}=\mathbf{2 4})$

\begin{tabular}{lc}
\hline Item & No. \\
\hline Age & \\
$\leq 44$ & 10 \\
$>44$ & 14 \\
Clinical stages & \\
Ia & 0 \\
Ib & 8 \\
Ila & 11 \\
Ilb & 5 \\
Pathological pattern & \\
Squamous cell carcinoma & 21 \\
Adenocarcinoma & 3 \\
Pathological grading & \\
I & 1 \\
II & 19 \\
III & 4 \\
Lymph nodes metastasis & \\
Yes & \\
No & \\
HPV infection & 3 \\
Positive & 21 \\
Negative & \\
\hline
\end{tabular}

through DNMT3A is required for HAVCR2 and LGALS9 transcription. The results showed that overexpressed SUV39H1 increased the methylation levels at the HAVCR 2 and LGALS9 promoter regions (Fig. 5a, b), these changed methylation levels contributed to the decrease of Tim- 3 and galectin- 9 expression among overexpressed SUV39H1 in cell lines (Fig. 5e). SUV39H1knocked-down cells showed the opposite results (Fig. 5c, d, f). To sum up, it was indicated that changing histone modification precede the alternation DNA methylation level of $H A V C R 2$ and $L G A L S 9$, indicating that SUV39H1 participated in changing the methylation status of HAVCR2 and LGALS9 by elevating the DNMT3A expression, so as to their transcriptional activity altered.

\section{SUV39H1 mediated Tim-3 and galectin-9 expression through DNA methylation in vivo}

For the purpose of investigating SUV39H1 mediated the costimulatory factors Tim- 3 and galectin- 9 expression through DNA methylation in vivo, we generated SiHaSUV39H1 and HeLa-SUV39H1 tumor xenografts in nude mice. As shown in Fig. 6a, tumors formed from the SiHa-mock and HeLa-mock cells (Fig. 6b, c) grew faster than those formed from the SiHa-SUV39H1 and HeLaSUV39H1 cells, respectively. These data indicated that up-regulating SUV39H1 inhibited the tumor growth in SiHa and HeLa cells.
To determine SUV39H1 mediated Tim-3 and galectin-9 expression through DNA methylation in vivo, the levels of H3K9me3, DNMT3A, Tim-3 and galectin-9 in the tumor xenograft tissues were examined by western blotting. As shown in Fig. 6d-f, the expression of DNMT3A increased significantly when SUV39H1 overexpressed, followed by the down-regulation of Tim-3 and galectin-9 in SiHa-SUV39H1 and HeLa-SUV39H1 cells derived tumors. SUV39H1 overexpression significantly up-regulated the methylation level of HAVCR2 and LGALS9 in tumor tissues (Fig. 6g). ChIP analysis revealed that SUV39H1 regulated the expression of DNMT3A by improving H3K9me3 level acting on the -1000 to +1 region of the promoter region of DNMT3A (Fig. $6 \mathrm{~h}$, i) in tumor tissues. These results indicated that SUV39H1 precede the changes in DNA methylation. All the results in xenograft tissues were consistent with those in vitro, illustrated that similar SUV39H1 mediated Tim-3 and galectin-9 expression through DNA methylation in vivo.

\section{H3K9me3 expression was independent from HR-HPV oncogenes}

As persistent HR-HPV infection contributes to almost all cervical cancer cases [18], we attempted to explore whether HR-HPV oncogenes E6 and E7 participated in SUV39H1 mediated DNA methylation in SiHa and HeLa cells. there was no difference in the expression level of H3K9me3 in cervical cancer cells SiHa, HeLa and C33A (Fig. 4e). Expression of HPV16/18 E6 and E7 oncogenes were detected by western blotting in overexpressed or knocked-down SUV39H1 SiHa and HeLa cells respectively. As show in Fig. 7i, j, the expression level of HRHPV oncogenes E6 and E7 were no difference between overexpressed or knocked-down SUV39H1 SiHa and HeLa cells with control. In the following studies we transiently overexpressed or knocked-down HPV16/18 E6 and E7 in cervical cancer cells for further illustration (Fig. $7 \mathrm{a}-\mathrm{d}$ ). The results showed that the level of H3K9me3 was not changed in overexpressed or knockeddown HPV16/18 E6 and E7 cells compared with control (Fig. 7e-h).

Taken together, our data suggested that H3K9me3 expression was independent from HR-HPV oncogene E6 and E7 in cervical cancer.

\section{Discussion}

Aberrant DNA methylation plays an important role in cervical cancer carcinogenesis, which causes silencing of certain genes $[19,20]$. Epigenetic modification also plays a crucial part in regulating immune cell differentiation $[21,22]$. The methylation status of immune genes affects the tumor immune response in the tumor microenvironment (TME) $[23,24]$. The study showed that reduced 

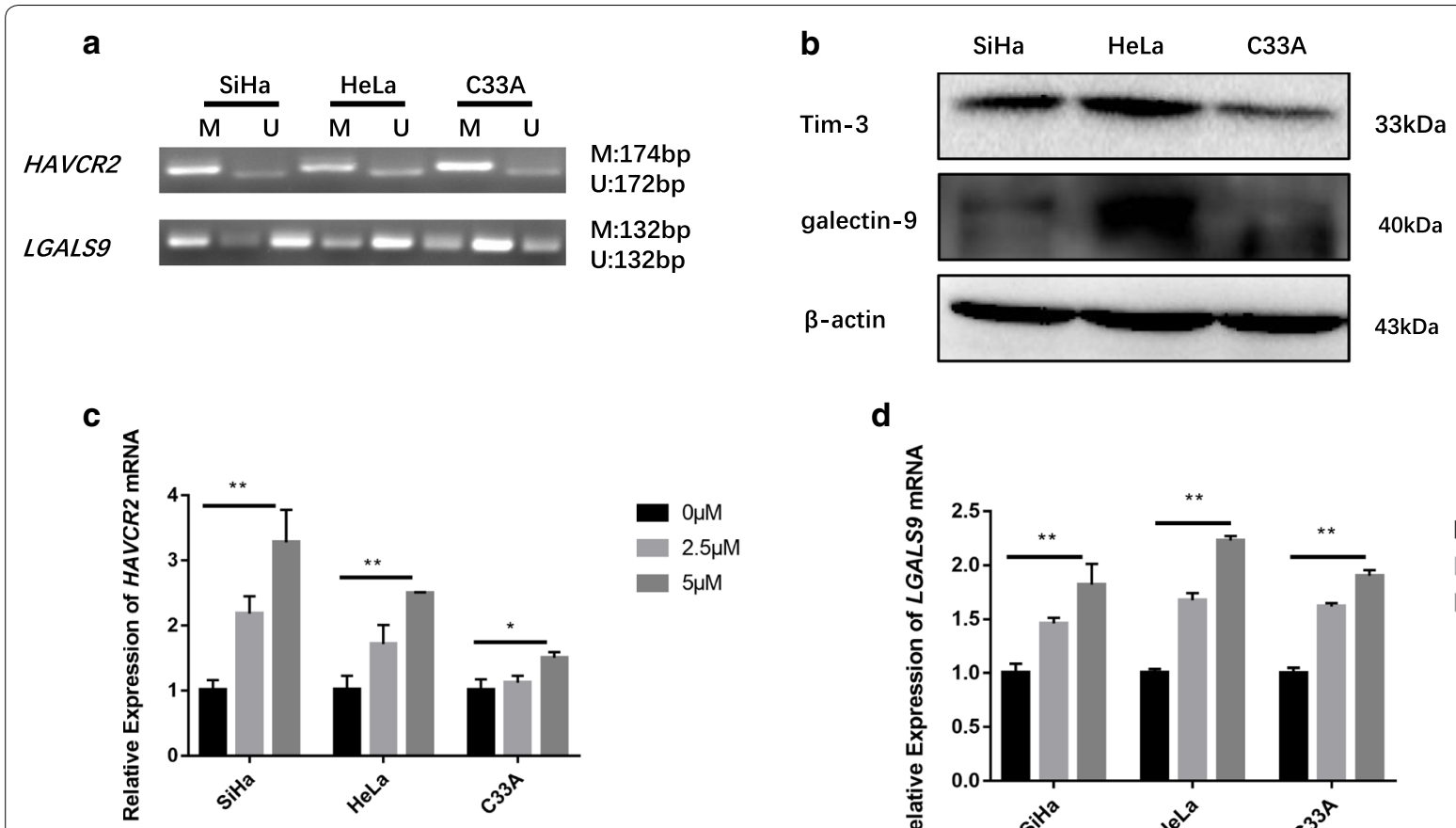

d
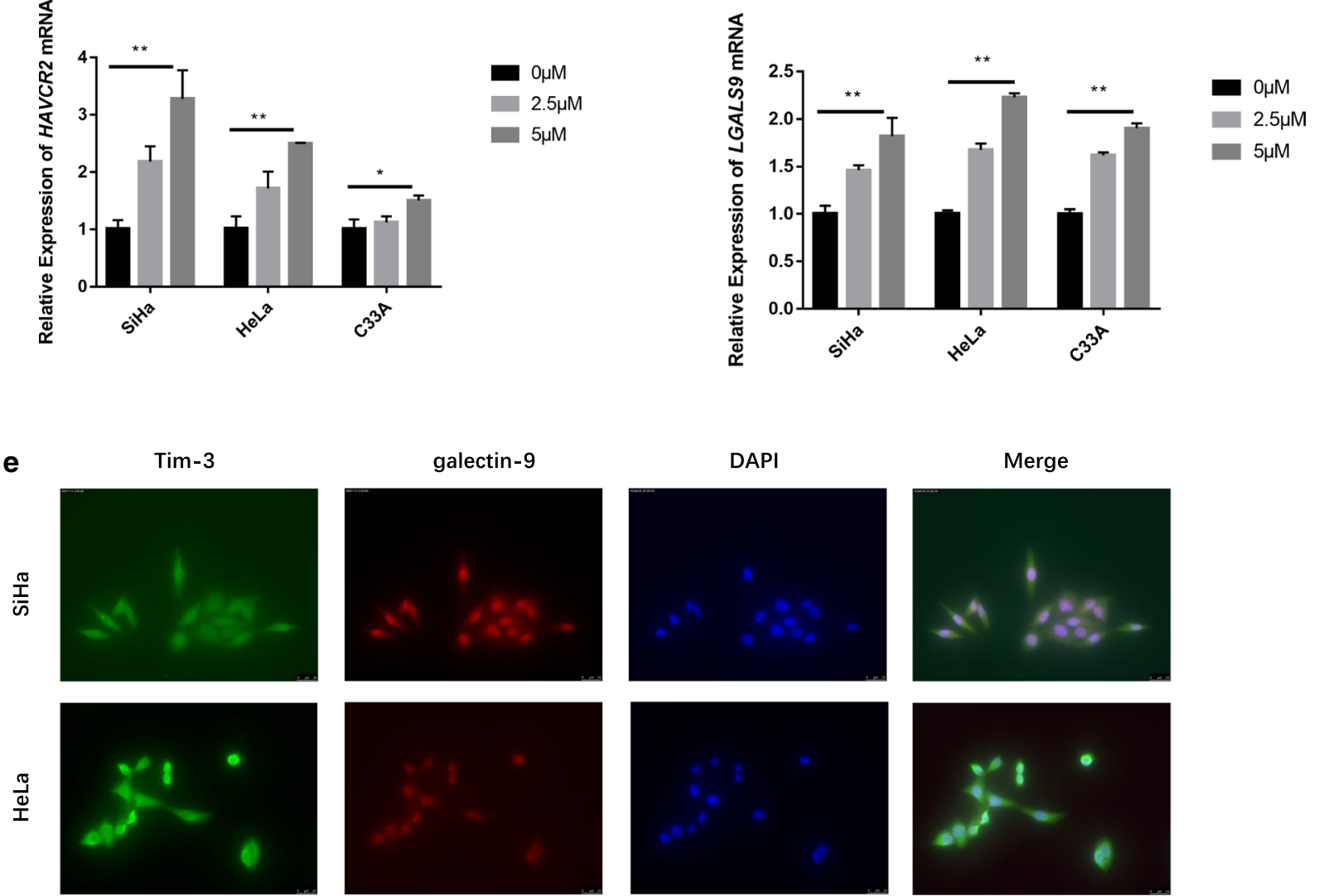

Fig. 2 Methylation status in the promoter regions of HAVCR2 and LGALS9 in cervical cancer cells. a Detection of HAVCR2 and LGALS9 methylation status by MS-PCR in SiHa, Hela and C33A cells; ( $M$ methylated, $U$ unmethylated). b Tim-3 and galectin-9 expressed in SiHa, HeLa and C33A cells detected by western blotting. $\mathbf{c}$, d Relative expression of HAVCR2 and LGALS9 mRNA in SiHa, HeLa and C33A cells after treatment with different concentrations of 5-Aza-CdR. e Representative immunofluorescence staining of Tim-3 and galectin-9 expression in SiHa and HeLa cells. ${ }^{*} P<0.05$, ${ }^{* *} P<0.01$

activity of DNMTs in $\mathrm{CD} 4^{+}$Tregs was accompanied by demethylation of the forkhead box P3 (FOXP3) gene promoter and downregulation of immune responses in the TME [25]. Hypermethylation associated SMAD family member 3 (SMAD3) silencing in CAFs, which was associated with aberrant response to exogenous TGF- $\beta 1$ [26]. Here, we identified a novel function of SUV39H1 regulates DNMT3A expression through elevating H3K9me3 level at the DNMT3A promoter region, which could mediate Tim-3 and galectin-9 expression through DNA methylation in cervical cancer. Tim- 3 and galectin- 9 are overexpressed in cervical cancer tissues, this biological effect is mediated through the aberrant epigenetic of Tim-3 and galectin-9, which is facilitated by the recruitment of DNMT3A to their promoter regions. Meanwhile, SUV39H1 contributes to Tim-3 and galectin-9 regulation by up-regulating the H3K9me3 level at the DNMT3A promoter region. 

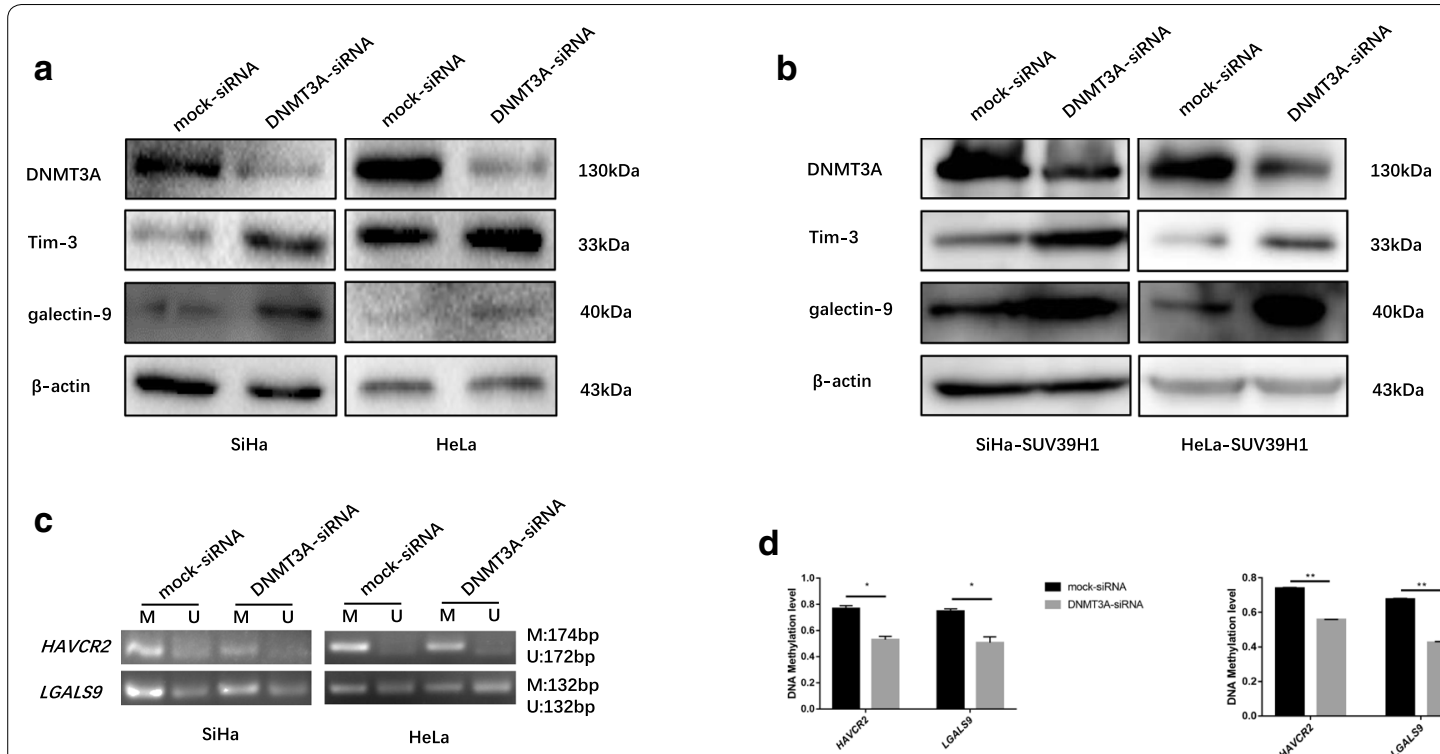

d
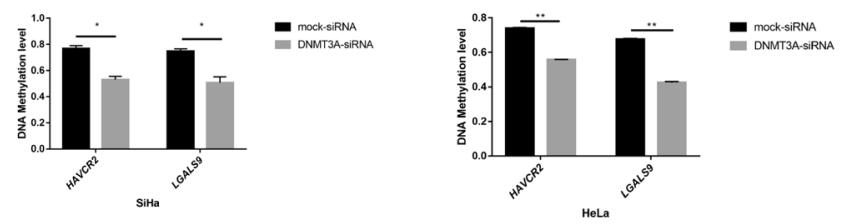
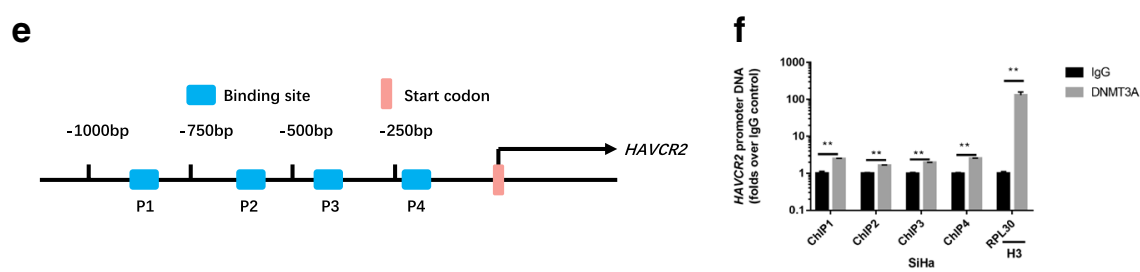

h

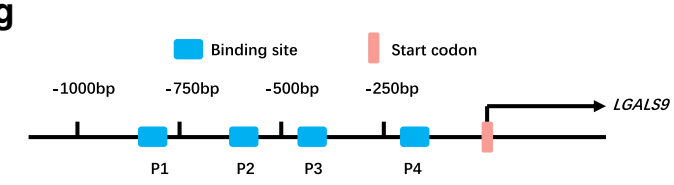

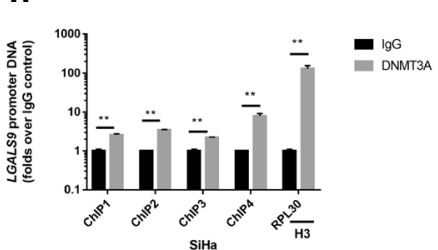

$\mathrm{SiHa}$

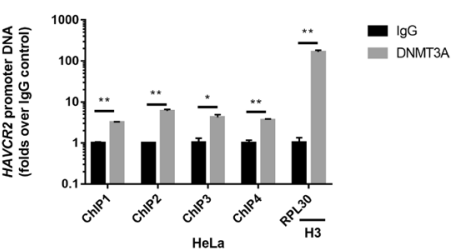

HeL

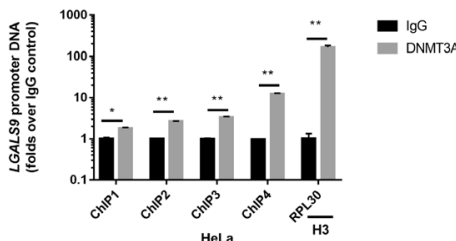

Fig. 3 Tim-3 and galectin-9 were repressed by DNMT3A mediated DNA methylation. a Western blotting analysis of SiHa and HeLa cells knocked-down DNMT3A against Tim-3, galectin-9 and DNMT3A. b Detection of the expression of DNMT3A and Tim-3, galectin-9 in DNMT3A specific siRNA transfected overexpressed SUV39H1 SiHa and HeLa cells by western blotting. c The methylation level of HAVCR2 and LGALS9 promoter regions were monitored by MS-PCR in DNMT3A knockdown SiHa and HeLa cells. d Methylated and unmethylated levels were quantified as $\mathrm{M} / \mathrm{M}+\mathrm{U} \%$ and $\mathrm{U} / \mathrm{M}+\mathrm{U} \%$, respectively. e, $\mathbf{g}$ Schematic representation of the four regions of the HAVCR2 and LGALS9 promoter regions amplified in the chromatin immunoprecipitation (ChIP)-quantitative PCR (qPCR) experiment. $\mathbf{f}$, $\mathbf{h}$ Chromatin was cross-linked, fragmented and immunoprecipitated with either lgG (mock) or anti-DNMT3A ChIP-grade antibody and the purified DNA was used to amplify with respective primer pairs for indicated four regions in the HAVCR2 and LGALS9 promoter regions in qPCR. The enrichment of DNMT3A on HAVCR2 and LGALS9 promoter regions relative to IgG in SiHa and HeLa cells, and $\mathrm{H} 3$ against $R P L 30$ was used as positive control. ${ }^{*} P<0.05,{ }^{*} P<0.01$

The study found that Tim-3 and galectin-9 were overexpressed in cervical cancer tissues related to promoter regions of HAVCR2 and LGALS9 were hypo-methylated, and they were partial methylated in cervical cancer cells, indicating DNA methylation mediating costimulatory factors Tim-3 and galectin-9 in cervical cancer cells. DNA methylation-based gene silencing in cancer [27]. DNMT3A involved in the induction of genes expression by directly binding to the HAVCR2 and LGALS9 promoter regions, suggested that DNMT3A participate in the epigenetic regulation of HAVCR2 and LGALS9 in cervical cancer. Knocked-down DNMT3A in cervical cancer cells caused a decreasing of HAVCR2 and LGALS9 methylation level, accompanied by the expression of Tim-3 and galectin-9 elevated.

H3K9me3 and DNA methylation leading to depression of a collection of genes $[28,29]$. The changes in histone modification precede the alterations in DNA 


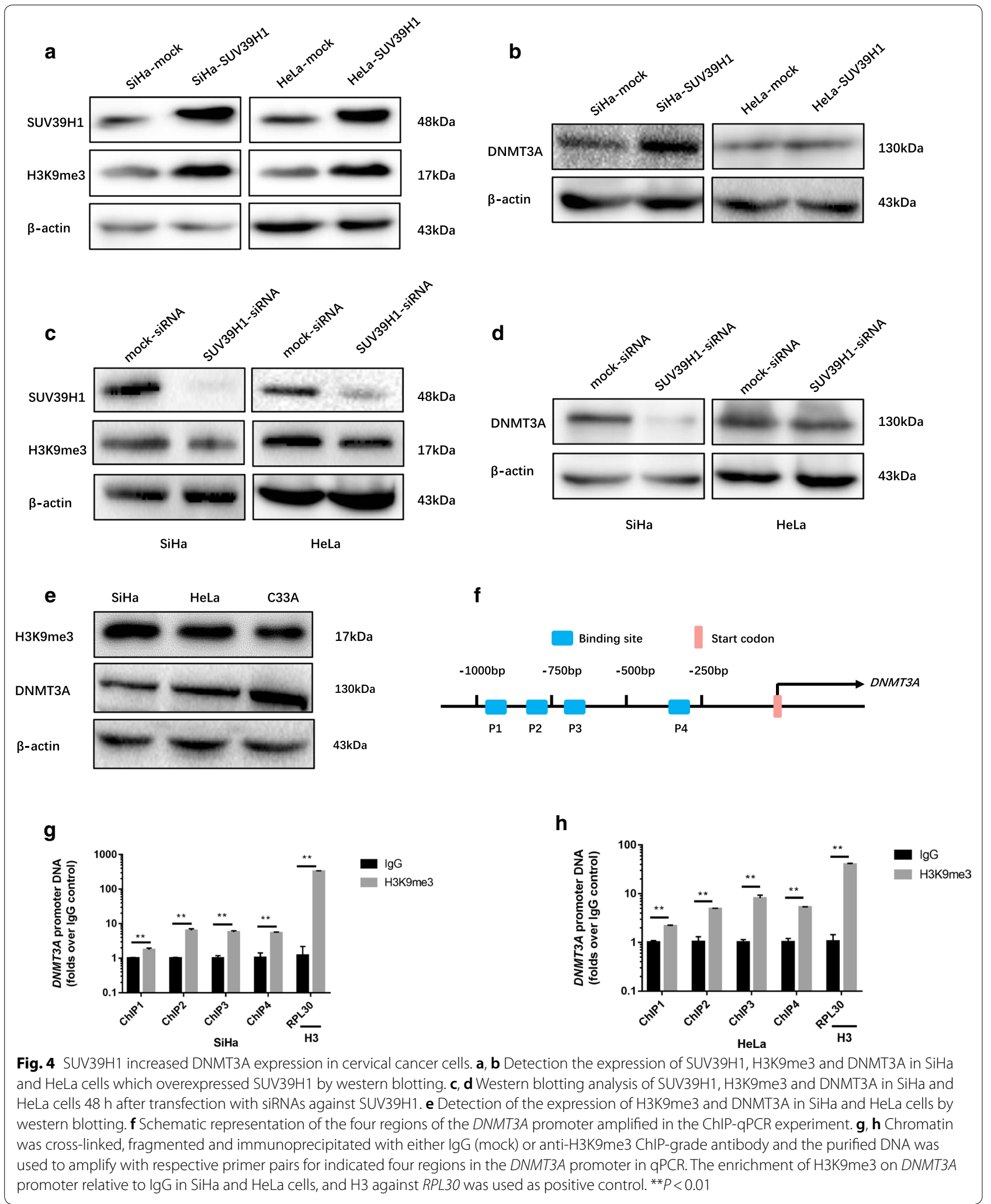




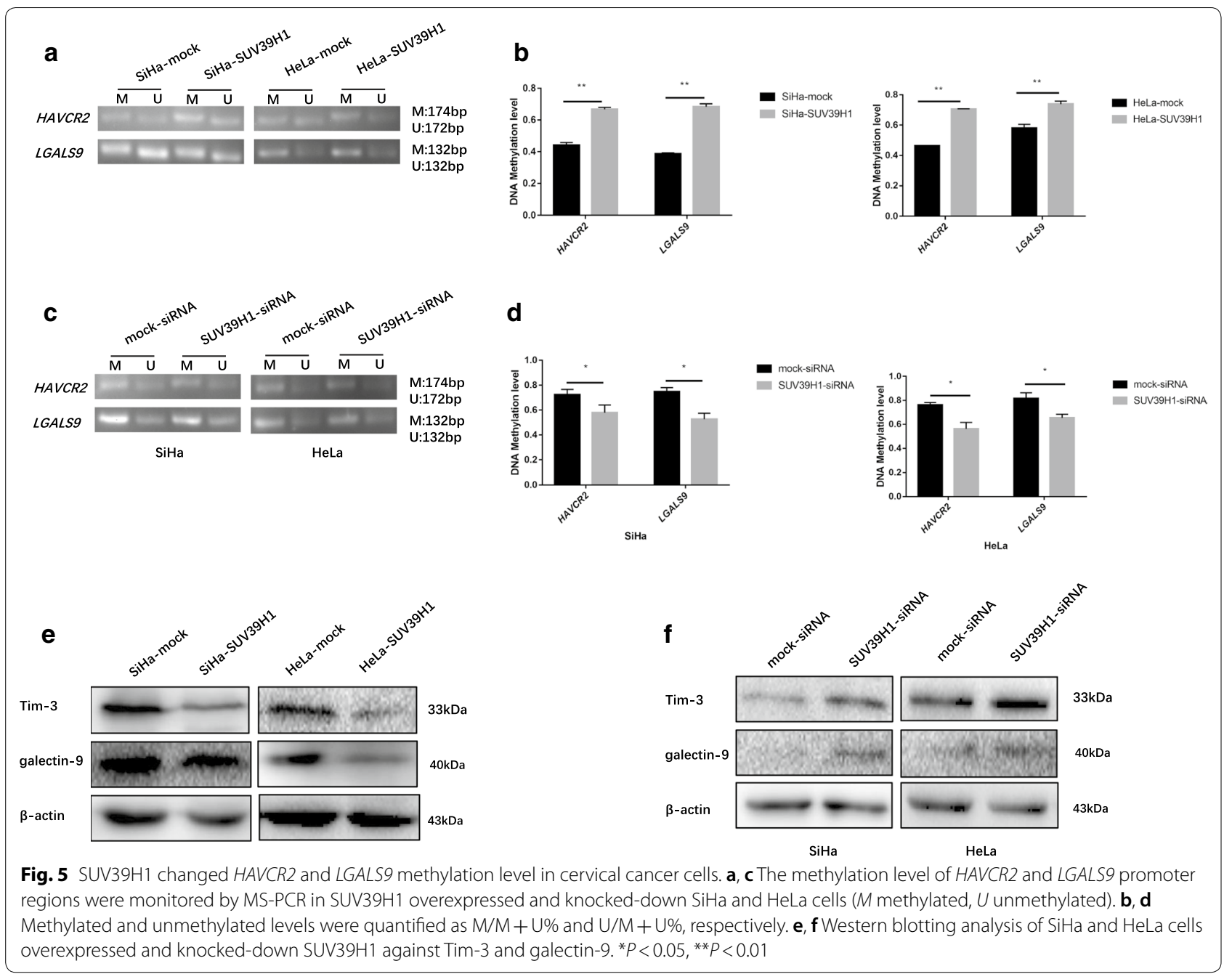

methylation [30, 31]. Up-regulation of SUV39H1 could promote DNMT3A expression, ChIP results demonstrated H3K9me3 expression level elevated at the DNMT3A promoter region to adjust its expression. These results suggested that SUV39H1 facilitates the expression of DNMT3A in cervical cancer. Overexpression SUV39H1 also associated with increased methylation level of $H A V C R 2$ and $L G A L S 9$ which in turn caused Tim-3 and galectin-9 expression decreased in cervical cancer. SUV39H1 may be a prerequisite for promoter DNA methylation by recruiting DNMT3A, they cooperatively orchestrate epigenetic modification at the gene promoter regions of HAVCR2 and LGALS9. But HPV16 or 18 oncogenes didn't affect the expression of H3K9me3 in cervical cancer cells.

The epigenetic regulation caused elevated expression of costimulatory factors Tim-3 and galectin-9 in cancer cells, and the abnormal secreted Tim- 3 and galectin- 9 by tumor cells lead to tumor microenvironment immune imbalance, thereby promoting the development of cervical cancer. We provide evidence for SUV39H1 as a potential therapeutic target, which could decrease negative immune factors like Tim-3 and galectin-9. Activation the expression of SUV39H1 may potentially be an effective approach to increase the efficacy of immune cells against cervical cancer.

\section{Conclusion}

In summary, the present study highlights the role of SUV39H1 and DNMT3A in the DNA methylation regulation of Tim-3 and galectin-9 in cervical cancer (Fig. 8). We provide a potential direction in exploring the relationship between SUV39H1 and DNMT3A. These findings add diverse roles and mechanistic insight into our understanding of crosstalk of SUV39H1 with DNMT3A. 

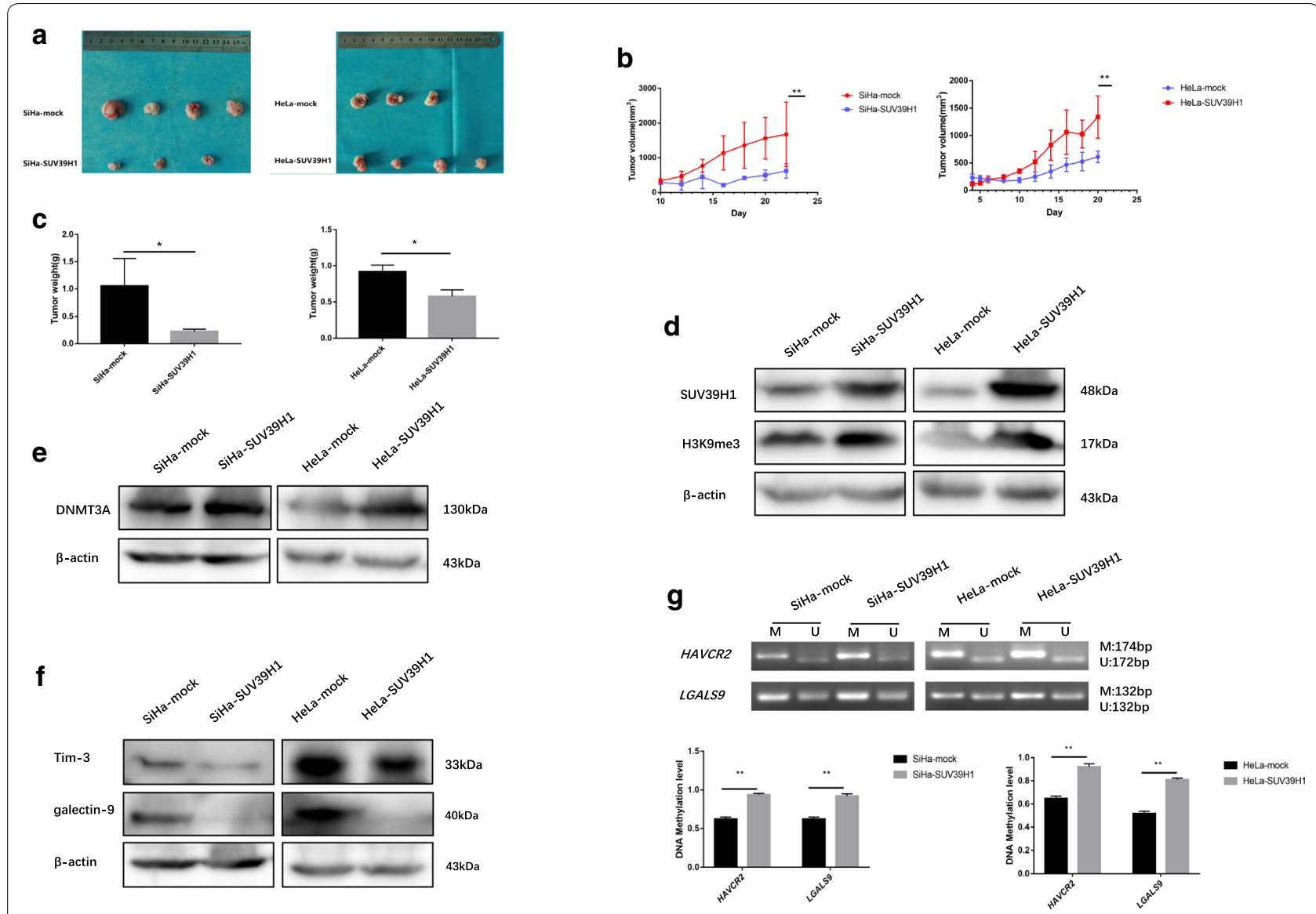

h

i
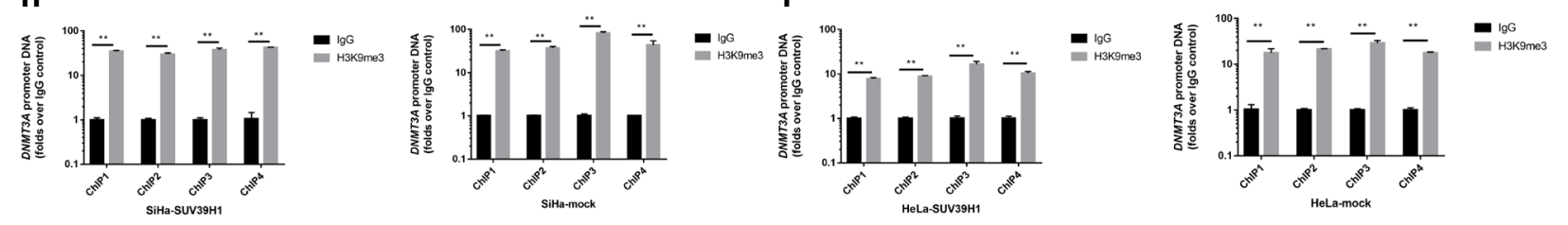

Fig. 6 SUV39H1 mediated Tim-3 and galectin-9 expression through DNA methylation in vivo. a SiHa-SUV39H1 and HeLa-SUV39H1 tumor xenografts in nude mice. b Tumors formed from SiHa-SUV39H1 and HeLa-SUV39H1 cells as well as tumor growth curves. c The tumors weight formed from SiHa-SUV39H1 and HeLa-SUV39H1. d-f Western blotting results of SUV39H1, H3K9me3, DNMT3A, Tim-3 and galectin-9 in SiHa-SUV39H1 and HeLa-SUV39H1 cells formed tumors. gThe methylation level of HAVCR2 and LGALS9 promoter regions were monitored by MS-PCR in tumor tissues. h, i Chromatin was cross-linked, fragmented and immunoprecipitated with either lgG (mock) or anti-H3K9me3 ChIP-grade antibody and the purified DNA was used to amplify with respective primer pairs for the indicated four regions in the DNMT3A promoter in qPCR. The enrichment of H3K9me3 on DNMT3A promoter relative to lgG in tumor tissues. ${ }^{*} P<0.05,{ }^{* *} P<0.01$

(See figure on next page.)

Fig. 7 HR-HPV E6/E7 wasn't participate in H3K9me3 mediated DNA methylation in cervical cancer. a-d mRNA levels in of HPV16 and 18 E6/E7-overexpressed C33A cells and of HPV16 and 18 E6/E7-knocked-down SiHa and HeLa cells. e, $\mathbf{f}$ Detection of the expression of H3K9me3 in HPV16 E6/E7 overexpressed C33A cells or knocked-down SiHa cells by western blotting. $\mathbf{g}, \mathbf{h}$ Detection of the expression of H3K9me3 in HPV18 E6/E7 overexpressed C33A cells or knocked-down HeLa cells by western blotting. i HPV16 E6/E7 expression in overexpressed or knocked-down SUV39H1 in SiHa cells. j HPV18 E6/E7 expression in overexpressed or knocked-down SUV39H1 in HeLa cells 


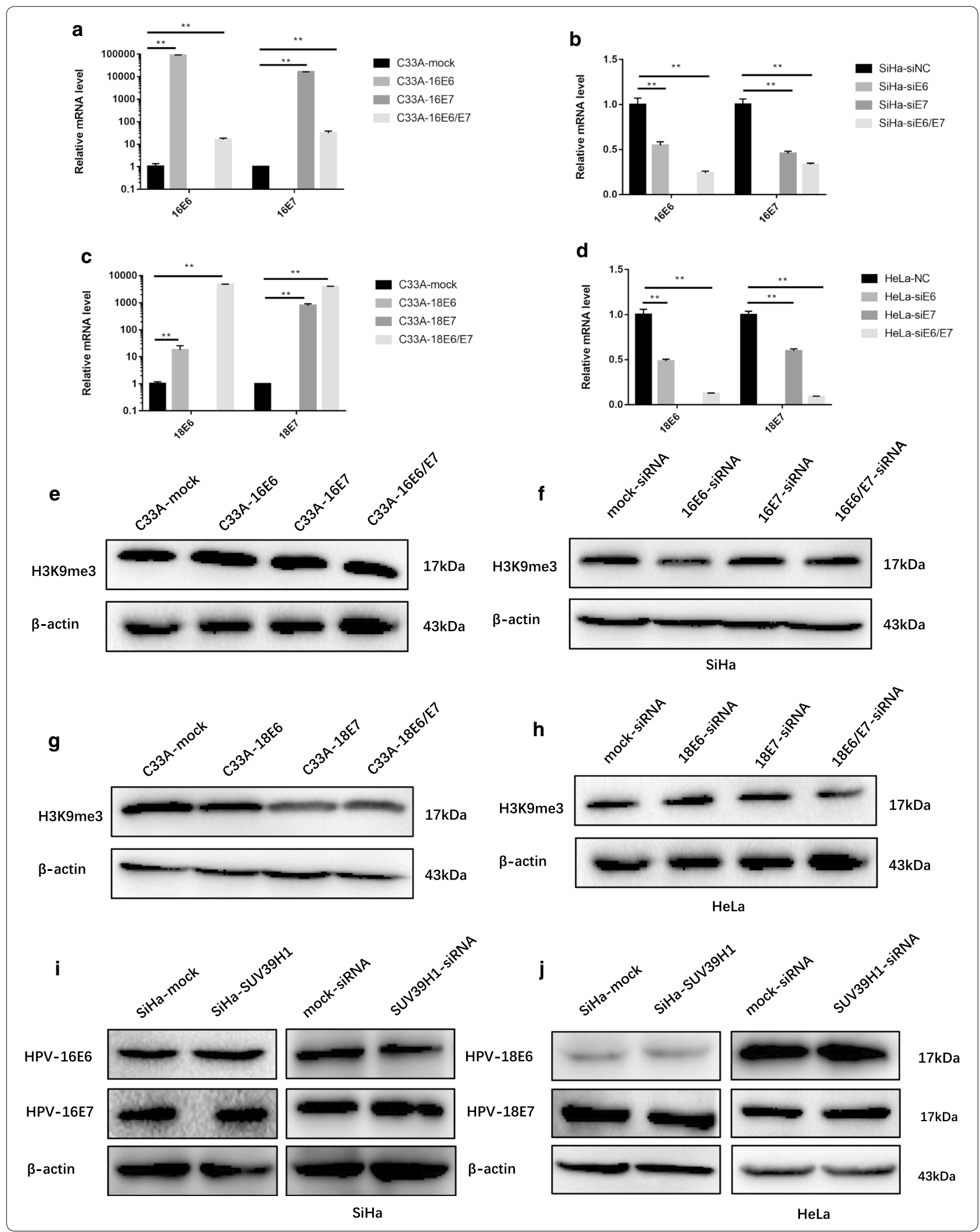




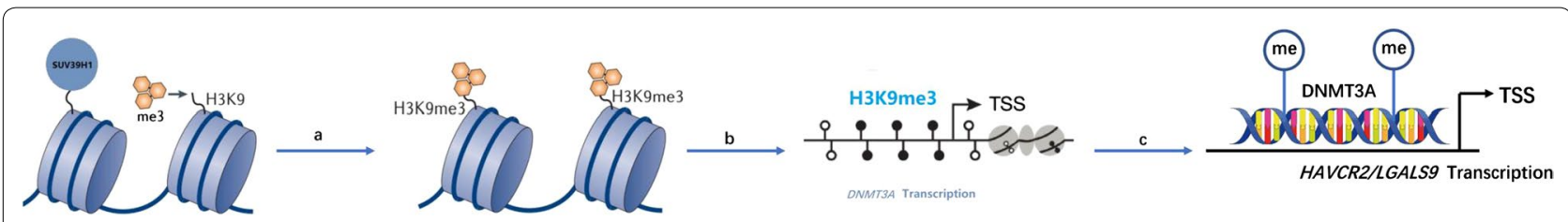

Fig. 8 The pathway of SUV39H1 regulated Tim-3 and galectin-9 expression through DNA methylation. a SUV39H1 mediated H3K9 methylation. b The expression level of H3K9me3 increased at the DNMT3A promoter region so that its expression up-regulated. c DNMT3A directly bind to HAVCR2 and LGALS9 promoter regions respectively to increase their methylation level so that their transcriptional activity decreased

\section{Acknowledgements}

We thank all the teachers in Center for Translational Medicine of the First Affiliated Hospital of Xi'an Jiaotong University for technical assistance.

\section{Authors' contributions}

$L Z$ and ST conducted the experiments. LZ, LS and XY participated in the data analysis. LZ, LS and XY designed the experiments. MZ, TY, SQ, QY collected samples from cervical cancer patients. LZ and XY wrote and edited the manuscript. All authors read and approved the final manuscript.

\section{Funding}

This research was supported by the National Natural Science Foundation of China, Grant/Award Number: 81472428, 81872225, a Fundamental Research Funds for the Central Universities, Grant/Award Number: 1191329115/1191329827, a Nutrition Asia Research Grant by BASF, Grant/ Award Number: 81672350

\section{Data availability statement}

The dataset analyzed during the current study are publicly available from the online database: GEPIA database (http://gepia.cancer-pku.cn/) and Oncomine database (www.oncomine.org).

\section{Ethics approval and consent to participate}

The study was approved by the Ethics Committee of the First Affiliated Hospital of Xi'an Jiaotong University (G-272) in Shaanxi, China. Written informed consent was obtained from all patients to participate in this study. BALB/C nude mice used in this study were obtained from Experimental Animal Center of Xi'an Jiaotong University (License number SYXK (Shaanxi) 2015-0002) and (Protocol number SCXK (Beijing) 2016-0006). This research complied with the revised Animals (Scientific Procedures) Act 1986 in the UK.

\section{Consent for publication}

Not applicable.

\section{Competing interests}

The authors declare no potential conflicts of interest.

Received: 21 April 2020 Accepted: 24 June 2020

Published online: 20 July 2020

\section{References}

1. Vu M, Yu J, Awolude OA, Chuang L. Cervical cancer worldwide. Curr Probl Cancer. 2018;42(5):457-65.

2. Bray F, Ferlay J, Soerjomataram I, Siegel RL, Torre LA, Jemal A. Global cancer statistics 2018: GLOBOCAN estimates of incidence and mortality worldwide for 36 cancers in 185 countries. CA Cancer J Clin. 2018;68(6):394-424.

3. Crosbie EJ, Einstein MH, Franceschi S, Kitchener HC. Human papillomavirus and cervical cancer. Lancet. 2013;382(9895):889-99.

4. De Nola R, Menga A, Castegna A, Loizzi V, Ranieri G, Cicinelli E, Cormio G. The crowded crosstalk between cancer cells and stromal microenvironment in gynecological malignancies: biological pathways and therapeutic implication. Int J Mol Sci. 2019;20(10):2401.
5. Li X, Hu W, Zheng X, Zhang C, Du P, Zheng Z, Yang Y, Wu J, Ji M, Jiang J. Emerging immune checkpoints for cancer therapy. Acta Oncol. 2015;54(10):1706-13.

6. Moriyama K, Kukita A, Li YJ, Uehara N, Zhang JQ, Takahashi I, Kukita T. Regulation of osteoclastogenesis through Tim-3: possible involvement of the Tim-3/galectin-9 system in the modulation of inflammatory bone destruction. Lab Invest. 2014;94(11):1200-11.

7. Zhang H, Song Y, Yang H, Liu Z, Gao L, Liang X, Ma C. Tumor cellintrinsic Tim-3 promotes liver cancer via NF-kappaB/IL-6/STAT3 axis. Oncogene. 2018;37(18):2456-68.

8. Yan J, Zhang Y, Zhang JP, Liang J, Li L, Zheng L. Tim-3 expression defines regulatory T cells in human tumors. PLOS ONE. 2013;8(3):e58006.

9. Nowacka-Zawisza M, Wisnik E. DNA methylation and histone modifications as epigenetic regulation in prostate cancer (Review). Oncol Rep. 2017;38(5):2587-96.

10. Bhat S, Kabekkodu SP, Varghese VK, Chakrabarty S, Mallya SP, Rotti $H$, Pandey D, Kushtagi P, Satyamoorthy K. Aberrant gene-specific DNA methylation signature analysis in cervical cancer. Tumour Biol. 2017;39(3):1010428317694573.

11. Zhang L, Tian S, Pei M, Zhao M, Wang L, Jiang Y, Yang T, Zhao J, Song L, Yang X. Crosstalk between histone modification and DNA methylation orchestrates the epigenetic regulation of the costimulatory factors, Tim3 and galectin9, in cervical cancer. Oncol Rep. 2019;42(6):2655-69.

12. Du J, Johnson LM, Jacobsen SE, Patel DJ. DNA methylation pathways and their crosstalk with histone methylation. Nat Rev Mol Cell Biol. 2015;16(9):519-32.

13. Lu C, Klement JD, Yang D, Albers T, Lebedyeva IO, Waller JL, Liu K. SUV39H1 regulates human colon carcinoma apoptosis and cell cycle to promote tumor growth. Cancer Lett. 2020;476:87-96.

14. Lu C, Yang D, Klement JD, Oh IK, Savage NM, Waller JL, Colby AH, Grinstaff MW, Oberlies NH, Pearce CJ, et al. SUV39H1 represses the expression of cytotoxic T-lymphocyte effector genes to promote colon tumor immune evasion. Cancer Immunol Res. 2019;7(3):414-27.

15. Wei X, Zhang S, Cao D, Zhao M, Zhang Q, Zhao J, Yang T, Pei M, Wang L, LiY, et al. Aberrant hypermethylation of SALL3 with HPV involvement contributes to the carcinogenesis of cervical cancer. PLOS ONE. 2015;10(12):e0145700.

16. Wang J, Yan W, Peng $X$, Jiang $Y$, He L, Peng $Y$, Chen $X$, Ye M, Zhuo H. Functional role of SUV $39 \mathrm{H} 1$ in human renal tubular epithelial cells under high-glucose ambiance. Inflammation. 2018;41(1):1-10.

17. Shirai A, Kawaguchi T, Shimojo H, Muramatsu D, Ishida-Yonetani M, Nishimura Y, Kimura H, Nakayama Jl, Shinkai Y. Impact of nucleic acid and methylated $\mathrm{H} 3 \mathrm{~K} 9$ binding activities of Suv39h1 on its heterochromatin assembly. eLife. 2017;6:e25317.

18. Zhang S, Batur P. Human papillomavirus in 2019: an update on cervical cancer prevention and screening guidelines. Clevel Clin J Med. 2019;86(3):173-8.

19. Vidal E, Sayols S, Moran S, Guillaumet-Adkins A, Schroeder MP, Royo R, Orozco M, Gut M, Gut I, Lopez-Bigas N, et al. A DNA methylation map of human cancer at single base-pair resolution. Oncogene. 2017:36(40):5648-57.

20. Xu W, Xu M, Wang L, Zhou W, Xiang R, Shi Y, Zhang Y, Piao Y. Integrative analysis of DNA methylation and gene expression identified cervical cancer-specific diagnostic biomarkers. Signal Transduct Target Ther. 2019;4:55. 
21. Schuyler RP, Merkel A, Raineri E, Altucci L, Vellenga E, Martens JHA, Pourfarzad F, Kuijpers TW, Burden F, Farrow S, et al. Distinct trends of DNA methylation patterning in the innate and adaptive immune systems. Cell Rep. 2016;17(8):2101-11.

22. Ali MA, Matboli M, Tarek M, Reda M, Kamal KM, Nouh M, Ashry AM, ElBab AF, Mesalam HA, Shafei AE, et al. Epigenetic regulation of immune checkpoints: another target for cancer immunotherapy? Immunotherapy. 2017;9(1):99-108.

23. Janson PC, Marits P, Thorn M, Ohlsson R, Winqvist O. CpG methylation of the IFNG gene as a mechanism to induce immunosuppression [correction of immunosupression] in tumor-infiltrating lymphocytes. J Immunol (Baltimore, Md: 1950). 2008;181(4):2878-86.

24. Cruz AF, de Resende RG, de Lacerda JCT, Pereira NB, Melo LA, Diniz MG, Gomes CC, Gomez RS. DNA methylation patterns of genes related to immune response in the different clinical forms of oral lichen planus. J Oral Pathol Med. 2018;47(1):91-5.

25. Ke X, Zhang S, Xu J, Liu G, Zhang L, Xie E, Gao L, Li D, Sun R, Wang F, et al. Non-small-cell lung cancer-induced immunosuppression by increased human regulatory T cells via Foxp3 promoter demethylation. Cancer Immunol Immunother. 2016:65(5):587-99.

26. Vizoso M, Puig M, Carmona FJ, Maqueda M, Velasquez A, Gomez A, Labernadie A, Lugo R, Gabasa M, Rigat-Brugarolas LG, et al. Aberrant DNA methylation in non-small cell lung cancer-associated fibroblasts. Carcinogenesis. 2015;36(12):1453-63.
27. Kulis M, Esteller M. DNA methylation and cancer. Adv Genet. 2010;70:27-56.

28. Yang Y, Liu R, Qiu R, Zheng Y, Huang W, Hu H, Ji Q, He H, Shang Y, Gong $Y$, et al. CRL4B promotes tumorigenesis by coordinating with SUV39H1/ HP1/DNMT3A in DNA methylation-based epigenetic silencing. Oncogene. 2015;34(1):104-18.

29. Ando M, Saito Y, Xu G, Bui NQ, Medetgul-Ernar K, Pu M, Fisch K, Ren S, Sakai A, Fukusumi T, et al. Chromatin dysregulation and DNA methylation at transcription start sites associated with transcriptional repression in cancers. Nat Commun. 2019;10(1):2188.

30. Meldi KM, Gaconnet GA, Mayo KE. DNA methylation and histone modifications are associated with repression of the inhibin alpha promoter in the rat corpus luteum. Endocrinology. 2012;153(10):4905-17.

31. Strunnikova M, Schagdarsurengin U, Kehlen A, Garbe JC, Stampfer MR, Dammann R. Chromatin inactivation precedes de novo DNA methylation during the progressive epigenetic silencing of the RASSF1A promoter. Mol Cell Biol. 2005;25(10):3923-33.

\section{Publisher's Note}

Springer Nature remains neutral with regard to jurisdictional claims in published maps and institutional affiliations.
Ready to submit your research? Choose BMC and benefit from:

- fast, convenient online submission

- thorough peer review by experienced researchers in your field

- rapid publication on acceptance

- support for research data, including large and complex data types

- gold Open Access which fosters wider collaboration and increased citations

- maximum visibility for your research: over 100M website views per year

At BMC, research is always in progress.

Learn more biomedcentral.com/submissions 